\title{
LA MUJER PROFESIONAL EN LA FAMILIA
}

\section{PROFESSIONAL WOMEN AND FAMILY PATTERNS}

Nita Gamio de Barrenechea ${ }^{1}$

\section{RESUMEN}

Considerando las estrategias analizadas en la cuarta Conferencia Mundial de la Mujer en Beinjing, sobre una mejor incorporación de la mujer a la fuerza laboral sin discriminación, promoviendo sus derechos económicos y su independencia, en el presente artículo, la autora hace un análisis reflexivo sobre el proceso de adaptación que debe de hacer la mujer para lograr acceder al mercado laboral, armonizándolo con sus deberes de madre y esposa para llevar adelante su hogar y su familia.

Palabras clave: Mujer, derechos de lamujer, no discriminación

\begin{abstract}
In this article, the author considers the strategies discussed at the Fourth World Conference on Women, held in Beijing, on the incorporation of women into the workforce without gender discrimination and on promoting their economic rights and their independence in order to make a reflective analysis on the process of adaptation that women must undergo in order to access the labor market, while harmonizing with their duties as mothers and wives and successfully running their homes and families.
\end{abstract}

Key Words: Women, Women's Rights. Non-discrimination. Women's Labor Rights.

Han pasado 18 años de la Cuarta Conferencia Mundial de la Mujer en Beinjing, donde se analizaron las estrategias de acción para la igualdad del hombre y la mujer y, con relación a esta última, para su mejor incorporación a la fuerza laboral, estrategias entre otras, como la de promover los derechos económicos de la mujer y su independencia, incluyendo el acceso al empleo, trabajo apropiado y mejores condiciones para el aprovechamiento de los recursos, así como eliminar toda forma de discriminación ocupacional, motivando que se armonice el trabajo con las responsabilidades familiares que deben asumir tanto el hombre como la mujer.

\footnotetext{
1 Docente Principal de la Facultad de Derecho, especialista en Derecho de Familia. Miembro del Consejo Asesor del Instituto de la Familia de la Facultad de Derecho de la Universidad Femenina del Sagrado Corazón -UNIFE. Fecha de recepción: 19 de setiembre de 2013.

Fecha de aceptación: 25 de setiembre de 2013.
} 
Sin embargo, analizando nuestra realidad, para la mujer no ha sido, ni sigue siendo nada fácil incorporarse a la fuerza laboral por los usos y costumbres de nuestra cultura y que viene desde nuestros ancestros, con características machistas para muchos -felizmente cada vez menos-, en el sentido que el hombre es el proveedor de la familia y la mujer "la reina de la casa", una reina cuya misión todavía se limita a cocinar, limpiar, lavar ocuparse de los niños y atender al marido. A Dios gracias, frente a esto, la mujer se ha rebelado y lo sigue haciendo; quiere seguir siendo la reina de la casa, pero con independencia de la billetera, al generar sus propios ingresos e incorporarse a la PEA (población económicamente activa), dejando de ser la PTSS (población trabajadora sin sueldo). El Ministerio de Trabajo y Promoción del Empleo informó recientemente que el número de mujeres correctamente empleadas en el país viene año a año incrementándose y el sub empleo ha disminuido considerablemente. Según datos del INEI, el $62.5 \%$ de mujeres ya se encuentran trabajando en labores que no son las que estrictamente llamamos "tareas del hogar". Vemos pues que vamos avanzando, quizá para algunos todavía lentamente, pero creo que por el camino correcto.

Es justo y válido que la mujer, al igual que el varón, tenga acceso a la fuerza laboral en igualdad de condiciones y se cumplan los principios de la Organización Internacional del Trabajo -OIT- de la no discriminación entre varón $\mathrm{y}$ mujer; igualdad de oportunidades $\mathrm{y}$, a igual trabajo, igual remuneración por trabajo de igual valor. En meses pasados, con motivo del Día Internacional de la Mujer, leí en un diario que "la independencia y el empuje laboral son hoy rasgos del sexo femenino"; inexacto, pues siempre lo han sido, como también otras de nuestras características como son la tenacidad, la persistencia, el deseo de superación, la creatividad, etc; sin embargo, nada o muy poco se podía hacer; ha sido un esfuerzo sin pausa, que sigue y debe seguir, pero lo que considero más importante para que la mujer pueda acceder a la fuerza laboral en la igualdad de condiciones que señala la OIT, tiene necesariamente que pasar por la capacitación; de un $10 \%$ luego de concluir la escuela que accedía a los estudios superiores hace medio siglo, hoy es del orden del $50 \%$ o más en términos generales, pues todavía en el campo, el índice de analfabetismo de la mujer supera al del varón y donde su salario es el $50 \%$ de lo que gana un varón por el mismo trabajo. Pero esto no sucede sólo en el campo; la brecha de ingresos sucede también en los empleos de las mujeres ejecutivas y profesionales que ganan la tercera parte de sus colegas varones por igual trabajo. Pero esto felizmente, - y con algo de ironía, pues mal de muchos es consuelo de tontos- no es exclusivo del Perú, también sucede en los países industrializados y en los llamados del primer mundo, donde las mujeres según la Organización para la Cooperación y Desarrollo Económico 
$(\mathrm{OCDE})$, ganan en promedio cinco veces menos que los varones y donde también como sucede en nuestro país, las mujeres todavía asumen la mayor parte del cuidado y atención de los niños. Tal vez lo que nos diferencia es que en esos países no existe tanto niño no reconocido; ni padres que no asuman sus obligaciones alimentarias, ni el gran número de madres adolescentes que ha aumentado en el Perú, en lo que Latinoamérica tiene la segunda tasa más alta después de África, no obstante que el índice global de fecundidad ha descendido. Casi una cuarta parte de las jóvenes latinoamericanas han sido madres antes de los 20 años.

Las mujeres, entonces, si pretenden acceder a la fuerza laboral a lo que también por cierto tienen derecho, deben contar con un cambio drástico en el modelo de familia tradicional y organizarse en una clara división de tareas entre las parejas para las labores del hogar. $Y$ esto debe ser entendido y comprendido por los varones. Hoy en día se da la paradoja que las mujeres comparten con su pareja el proveer ingresos, sin embargo no encuentran todavía el correlato, pues los varones no han asumido la responsabilidad de cooperar en las tareas domésticas. El ingreso de la mujer a la fuerza del trabajo ha tenido efectos importantes como la generación de riqueza en los países, el bienestar material de los hogares y la disminución de la pobreza. Pero frente a ello, encuentro que las tensiones en la familia se han incrementado y también se ha resquebrajado la estructura familiar o, tal vez, como lo señalo, deberíamos empezar a pensar en otra forma de familia, materia de reflexión y estudio que tampoco me atrevo a señalar si esta transformación podría tener mejores resultados, frente a la crisis reconocida por todos que está sufriendo hoy en día la familia en su conjunto, y de la cual se está culpando al alejamiento de la mujer del hogar para asumir otros trabajos fuera del mismo.

¿Cómo se puede conciliar el que la mujer esposa y madre pueda también realizarse en una actividad laboral fuera del hogar? La prioridad en la vida para ambos, debe ser siempre el hogar y la familia, y luchar por ello y si en algún momento de la vida tiene la mujer que escoger entre el éxito y la familia, elegir a ésta última, pues el éxito es efímero y pasajero y la familia es la que nos debe acompañar hasta el último día de nuestra vida, no por obligación, sino por cariño, y luchar por ese proyecto de vida que empezaron con tanta ilusión; fidelidad y respeto mutuo; paciencia y tolerancia para tener siempre presente que no somos perfectos y menos podemos pedir perfección; poca vida social: reuniones familiares sí, no de las otras, porque muchas veces las personas buscan aturdirse o salir a buscar fuera lo que no encuentran en casa; orden y organización en los horarios; evitar llevarse trabajo a la casa y menos el fin de semana o días de fiestas para poder pasarlos juntos con los hijos; mucha 
comunicación; hablar e intercambiar opiniones sobre los proyectos, aspiraciones, sueños, ilusiones; mucho amor, pues la mejor forma de recibir amor, es dar amor; nunca pasar de un día a otro disgustados, sin haberlo aclarado y ofrecer las disculpas del caso; mucha comprensión; respetar los silencios; mucha colaboración; interesarse en el trabajo del otro; coincidir ambos en la corrección y disciplina de los chicos sin desautorizarse; preocupación y apoyo del uno con el otro en momentos difíciles que nunca faltan, y el saber cada uno que puede contar con el otro para todo lo que necesite, pues eso da mucha seguridad. $Y$ esta receta es para ambos en partes iguales; si ambos cónyuges no miran hacia el mismo objetivo y diría con los mismos ojos, uno sólo no puede llevar a cabo la tarea. Y para concluir, me disgusta mucho cuando se habla del sacrificio de la mujer ¿cuál sacrificio? ¿y por qué alguien debe sacrificarse? ¿y, en todo caso, por qué la mujer? Si hay amor, cariño, afecto, respeto, comunicación entre los cónyuges y de éstos con sus hijos, no hay sacrificio posible. Todo esfuerzo o trabajo de ambos padres a favor de los suyos, si es hecho con amor, está plenamente justificado para la relación plena y una familia feliz.

\section{REFERENCIAS}

Organización de las Naciones Unidas (1995) Informe sobre la Cuarta Conferencia Mundial sobre la Mujer. Disponible en: http://www.un.org/womenwatch/daw/beijing/pdf/Beijing\%20full\%20report $\% 20$ S.pd. Consultado el 10 de setiembre de 2013. 